\title{
A penny for your thoughts
}

\author{
U. A. Yajnik* \\ Physics Department, Indian Institute of Technology Bombay, Powai, Mumbai 400 076, India
}

E. C. G. Sudarshan had a 'royal' personality. He enjoyed attention and in return he liked to delight you with clever jokes. He also relished food and was a great cook himself and loved to entertain people over home-cooked dinners. His discussion on physics problems was always threadbare, in the most down-to-earth tones, again interspersed with jokes. But throughout, his demeanour carried a childlike curiosity and avid persistence for simplification and clarity. During the years I knew him, he was perhaps at a critical juncture in life, expecting to receive the highest world recognition for at least one of his several seminal contributions to twentieth century physics. He travelled a lot, and spent a semester each at Göteborg in Sweden and at Harvard. As a student who had directly arrived from India, unfamiliar with the intense professional atmosphere of theoretical physics in the USA, I was oblivious to much of this, and could piece it together only during my later years. During his long absences I kept myself busy under some other professor's guidance or interacted with the many postdocs and students on the 'ninth floor' of the RLM building ${ }^{1}$.

I arrived at the University of Texas at Austin in Fall of 1980. I had just completed my five-year integrated M Sc degree from IIT Bombay. We had some of the very best teachers and I had also attended the National Science Talents Search summer schools. But nothing had prepared me for the intense research environment of a US university. Particularly, the 1970 s had been a grand extravaganza of breakthroughs and consolidations in elementary particle physics ${ }^{2}$. I was completely unaware of any of this, though the one thing I was aware of was that a Quantum Theory of Gravity was the holy grail and I had started with reading Differential Geometry.

Thus, it was upon arrival that I signed up for the General Theory of Relativity courses being taught as a two part sequence by John A. Wheeler. Wheeler had the knack of finding sufficient number of topics to be able to choose from for a term paper for the whole class of 40 . There were also a few smaller course projects. Thus I ended up reviewing or solving some interesting topics that Wheeler was interested in. He was delighted with the second semester's term paper and suggested that it should be converted into a paper. In the course of working out the details of spinor functions on a toroidal manifold, I began asking around if anyone knew about existing literature. Soon enough I found a five-author paper on the

*e-mail: yajnik@iitb.ac.in so called 'eth' operator (a Hebrew alphabet that looks somewhat like the partial derivative symbol with a cut on it). One of the authors of this 1967 J. Math. Phys. paper was none other than George Sudarshan. Thus, trying to resolve what boundary conditions to use for selecting the complete basis subset of the general hypergeometric function solutions, I barged into Sudarshan's office. I started writing on the board and claimed that perhaps the authors of that paper had missed half of the basis set of the fermionic wave functions.

George was in a relaxed mood and he heard it all out. The eth symbol was also providing a conversation topic. Then, while he was making his comments, I was trying to spin a penny that was lying on top of a file cabinet close to the black board. He said 'if you have discovered an alternative basis set, that will be a minor discovery. But if you have discovered that we missed half the basis set, then it will be a major discovery. Now you can take that penny as a gift'. I departed in great cheer at this brief but happy discussion, tossing the penny, and that was my first discussion with the great physicist.

I subsequently moved away from General Relativity and George by then was teaching a Special Topics course on Grand Unification. So I signed up to work with him. But he was going off on a sabbatical; so I was to work with Charles Chiu. Charles was a very gentle and soft spoken professor. He suggested to me to study lattice gauge theory, and helped me work through the literature over a summer. But those years were also the heyday of the Inflationary Universe, and the unified models of particle physics were seen to play a significant role in the early Universe. Thus it was George who later suggested to me that I read Kibble's work on phase transitions in the early universe. Alan Stern who was then a postdoc suggested a problem to me and after we had a solution he was kind enough to write it as a paper. That was my first paper. But when George returned from one of his long absences and heard the details, he did not seem to 'like' it at all. He listened and showed some clinical interest, but his heart was not in it. This was another of his traits that I associate with his royal personality. He had strong likes and dislikes. Rationality is not known to be a key ingredient of creativity, yet these strong predilections were a little enigmatic.

Somehow General Theory of Relativity and Cosmology did not fascinate him at all. He held such a strong grudge about this that he almost did not read my thesis since later on it became increasingly focused on 
cosmological phase transitions. Also, this work with Alan contained a verification of the concept of fractional fermion number which was then becoming popular. $\mathrm{He}$ disliked it all. He had a deep knowledge of the extensive discourse on the structure of quantum field theories and was fully aware of all the liberties one has to take even with the relatively modern framework of Hilbert Space theory. And somehow in his mind our result did not sit well with that discourse and it irked him a lot.

But his 'dislike' for our work provoked his intense childlike curiosity, the need to 'fix it'. Indeed his ethos is well captured in the aphorism ${ }^{3}$, 'one works in Physics because something about it bothers us'. Luckily, around the same time Utpal Sarkar arrived as a postdoctoral fellow. He was a very pleasant and friendly person. But he had worked on very different topics and it took us some time to break the ice. He then bought a brand new car. But he either did not have a driving license or was not confident enough to drive it. I had not invested in a car but some friends had taught me driving by way of introduction to the American way of life. Utpal figured out that the best way to have George's exclusive attention was to barge in on him at his home. Thus we together would drive up to George's nice ranch house style home in North Austin in the morning. He would be in his dhoti taking care of something in the garden while carnatic music played in the background. We made ourselves tea or coffee and it was an atmosphere most conducive to creativity. On one of these occasions he picked up a pad and started writing and arguing with me how fractional fermion number must be avoided; and I armed with the then current literature kept arguing back and telling him why his objections did not hold. Finally he understood all the avenues to the issue, and then he found his fix. It was a solution implicitly requiring the existence of an auxiliary system, but easy to realize in principle. Fractional number can be avoided. Thus came out our short paper which I thought was as insightful as some of the other papers on the topic that had appeared in Phys. Rev. Lett. around then. George was skeptical it would be accepted by $P R L$ and indeed it got transferred to Phys. Rev. D.

One happy occasion that I managed to attend was owing to Swadesh Mahajan. In 1983, Abdus Salam visited Austin. The following year he created the Third World Academy of Sciences at International Centre for Theoretical Physics (ICTP). This Academy would also award prizes in recognition of scientific contributions. The first recipient of the Physics prize of the Academy was George. Faculty colleagues from the Department were going to toast him at the Faculty Club. Swadesh somehow smuggled me into this faculty-only program. It was heartening to hear Steven Weinberg give a speech celebrating George's achievements and the recognition. I remember him especially saying with a chuckle, 'and ten thousand dollars is not a small amount either'.
Champagne or bubbly wine was being consumed and that may have been the first time ever that I sipped some. Swadesh also took a nice picture of me standing between the two great stalwarts of Weak Interactions. But the many moves I made later and the Mumbai monsoon seem to have finally taken a toll on that photograph.

In Spring 1986 Weinberg was teaching String Theory. The subject had deep links to the old S-matrix theory. But the new formulation and the new emphasis as a fundamental theory of Gravity made the treatment completely different. And Weinberg who was teaching it for the first time was as thorough and fluent with it as he had been with his Quantum Field Theory courses which had been his favourite themes since the 1960s. George too started sitting in on this course. I was attending the course but I was also writing my thesis; so, occasionally caught up with George when the class ended. And then we would go for lunch together. On one of these occasions, leaving one of the more rigorous and brilliantly crafted lectures, he said 'Weinberg is like a rishi. He "sees" the truth of the equations, and much farther beyond. The symbols are just a way of representing.' Then on another occasion, munching burritos on the 26th Street, and knowing my anguish and struggle with writing the thesis, yet not doing anything actively for it, he said, 'this is one of the most difficult times a person can have. At this point he hates his research topic, doubts his own results, he hates the subject, he hates the department, he hates the advisor, ... one should not interfere with him at all.' And all my anguish melted away in a cathartic laughter.

After those days, the one time I ran into him was in late 1993. I was on my way to Chennai for IIT work. And ahead of me in the queue, getting into the flight was this relaxed looking gentleman in a safari suit. It was George. On the flight he chatted nicely about many things. He did not disagree when I said left-right symmetric models (originated by Jogesh Pati and Abdus Salam) had the best of both the worlds. They possess the elegant chiral symmetry (a key point highlighted by Sudarshan and Marshak) and yet make the world even handed. Him not disagreeing was as good as an endorsement and an encouragement to work on it, and that is exactly what I did over the few decades to come. As we parted, he gave me his number and said to call him after my work was over. Indeed on the evening that the work was finished a car arrived to pick me up at the IIT Campus. He took me along with his friends and family for a nice dinner.

Many years later it became possible to invite him to IIT Bombay. During our Golden Jubilee celebrations, as a part of a series of distinguished visitors we had, he and Bhamathi came in July 2008 to spend a week at IIT Bombay. His lectures were enjoyed and well received by faculty members from many disciplines. By now I was much matured and could hold forth with him on many themes. So in between his schedule of lectures, I would 
barge into their guest house room and thus got his views on many issues in physics and on life in general. He had by then become a relaxed person, having come to terms with the vagaries of the way in which formal symbols of glory are distributed in the world. He cracked jokes and highlighted several ironies of the situation in his characteristic style, but seemed to not hold much of a grudge. But even after all those years, I could detect his dislike of General Relativity and Cosmology. And I will never know the reason for that.

Finally in 2014, Resonance editors kindly gave me the task of interviewing him for the Face to Face Section. I had to track down his movements to be sure when he would be in Chennai at IMSc. I went with my daughter who was by then becoming a professional photographer. I so much wanted her to meet him, not only because he was a personality of such distinction, but also perhaps so that she may understand the sources of some of my attempted jokes better. Over those two days we had a lot of chats and the crux of it got written up as the article that got published.

I should thus end with one joke he told me during one of our exchanges as student and teacher. It illustrated well why one would never win an argument against him. There were two Rabbis, a novice and a master, who spent a long evening discussing matters of religion and morality. They realized quite late that they were hungry. And when they got to the market all the shops were closing. One shopkeeper had just two fish left which he was willing to give them, and one fish was big but the other one was somewhat small. With not much choice, the novice took them and brought the fish and offered them first to the senior. The master took the larger of the fish. Then they both ate in silence. But once through, the novice due to the long debates they had, was emboldened to point out to the master, 'You know, if I were you I would have taken the smaller fish'. At this the master said, 'but that is what you got, so why are you complaining?'

The physical penny I received sat in a special place on my desk for a while but eventually went the way of most pennies. But the challenge to convert the occasion of a minor discovery into the opportunity for a major one remains with me as a felicitous gift. Physics continues to grow into a burgeoning edifice of subtle evidence, ingenious theories and elegant consolidations. But behind the glory of all the successful theories there lurk certain or yet to be ascertained paradoxes. So long as they continue to bother us the way Physics bothered George, exciting adventures and delightful resolutions remain in store.

1. Robert Lee Moore Hall, the 19 storeyed Physics Math Astronomy building at the junction of 26th Street and Speedway Street.

2. 'And what a triumph it was [of Quantum Field Theory] in the old sense of the word: a glorious victory parade full of wonderful things brought back from far places to make the spectator gasp with awe and laugh with joy' - Sidney Coleman in preface to 'Aspects of Symmetry'.

3. There is some likelihood he uttered this himself. 